\title{
UNIVERSAL INFRASTRUCTURE OF M2M ENABLED INTER-CLOUD SERVICES FOR INTELLIGENT TRANSPORTATION SYSTEM
}

\author{
ANKUSH RAI*, JAGADEESH KANNAN R \\ School of Computing Science \& Engineering, VIT University, Chennai, Tamil Nadu, India. Email: ankushressci@gmail.com
}

Received: 13 December 2017, Revised and Accepted: 10 April 2017

ABSTRACT

Objectives: The objective of this study is to develop the design of a generic infrastructure for on demand applications for intelligent transport systems in an urban area.

Methods: The main idea of the study is to allow seamless service composition and consumption but also to allow rapid deployment of new services through the pooling of different devices and access networks that may be owned and operated by different actors such as telecom operators, transportation service operators, and governmental organizations.

Results and Discussion: This research serves the solution for the problem of interoperability between different devices, on the fly device reconfiguration and service discovery.

Keywords: Internet of things, M2M communication, Intelligence Transportation system.

(C) 2017 The Authors. Published by Innovare Academic Sciences Pvt Ltd. This is an open access article under the CC BY license (http://creativecommons. org/licenses/by/4. 0/) DOI: http://dx.doi.org/10.22159/ajpcr.2017.v10s1.19648

\section{INTRODUCTION}

The provision of an efficient intelligent transport systems (ITS) communications infrastructure requires the deployment of multiple devices across the urban area at fixed locations such as bus stations, intersections, or along the roads, but also within the transportation vehicles such as buses, taxis, bikes, or even users' vehicles [1-4]. From a transportation service provider's perspective, such dense network is used for different ITS applications such as providing transport information (bus schedule, bikes' availability, incidents, etc.). The same infrastructure augmented with the appropriate sensors can be used by a governmental organization for applications such as (1) congestion map computation/forecast [5,6], (2) vehicles classifications for statistics purposes [7], or (3) monitoring (air pollution, road quality, etc.) [8-10].

In today's transportation sector, the traffic conditions are monitored by cameras and motion sensors set along significant road intersections and thruways. On the other hand, with growing street activity and confined spaces for road expansion, these detecting innovations are coming as far as possible in giving ongoing traffic updates to ease traffic clogs and avoiding mishaps [11]. The developing pattern for figuring out the solution of such problems lies in the internet of things (IoT) empowered automotive industry to furnish vehicles with devoted internet based short-range inter-communicative devices to give vehicle-to-vehicle correspondences and subsequently to enhance traffic safety and give better traffic perceivability for its administration [12-14]. Case in point, when there is a congested driving condition, the first automobile might tell the other automobiles behind if there is a mischance, and this will in the end illuminate the astute route frameworks to recourse the way to another less swarmed street. These IoT-enabled automobiles or busses can make breakdown calls when suitable, gathering information about the encompassing infrastructures, for example, traffic lights and building structures, and about itself (for example, the broken parts in the vehicle and kind of load/stock/cargo it is hauling) in the occasion of a crisis [15]. Streaming such real-time data to cloud servers and processing it for real-time analytics purposes where information is considered as information in movement and diagnostic handling is required to be completed progressively with goals such that that decision choices can be made in a matter of seconds [16]. For instance, this necessity is normal in the transportation sector where intercommunication between vehicles regarding the onward speeding vehicle shall be intimidated or in situations concerned with ongoing traffic data enable drivers to enhance their courses and voyaging times. Vehicles gradually get to be "smart things" which can respond to the situations, taking into account ongoing circumstances in traffic, enhances transport utilization, automated monitoring of carbon emissions, drop in rate of traffic accidents, oversee traffic load and add to a more secure traffic system. In this study, we present the cognitive architecture for IoT-based intelligent transportation system by availing solution for interoperability between devices for M2M communication and availing cloud services on streaming data.

\section{METHODS}

The proposed IoT architecture can be straightforwardly spoken to by three classes of interconnected systems: Sensing (infrastructure) layer, communication layer, and service layer where stream analysis is done on cloud to encourage the service creation and solution layer to guarantee solid and secure bi-directional communication of data among these systems (Fig. 1). The proposed IoT solution for ITS obliges things to either be intelligent so they can channel and oversee information locally and give this usefulness. The communication infrastructure involves network and cloud through and through to encourage the control information movement stream associating cloud to IoT gadgets equipped vehicles. The Internet is a worldwide arrangement of interconnected IP networks that connects the computing system altogether. This system foundation, involving switches, aggregators, passages, repeaters, and different gadgets that control information movement stream, additionally interfaces with telecom and link systems (e.g., 3G, 4G/LTE) worked by service suppliers. Server farm/cloud infrastructure: Data focuses and cloud base contain extensive pools of virtualized servers and capacity that are arranged together. Supporting IoT, this infrastructure runs applications that investigate information from gadgets and sensors keeping in mind the end goal to create noteworthy data utilized for services and choice making $[17,18]$. Along these lines, returning the last decisions back to the IoT-equipped vehicles.

The e number of M2M devices e is divided into three classes: Device initial readiness be $i_{\alpha^{\prime}}$ operating M2M devices denoted as $u_{e}$ and loitered 


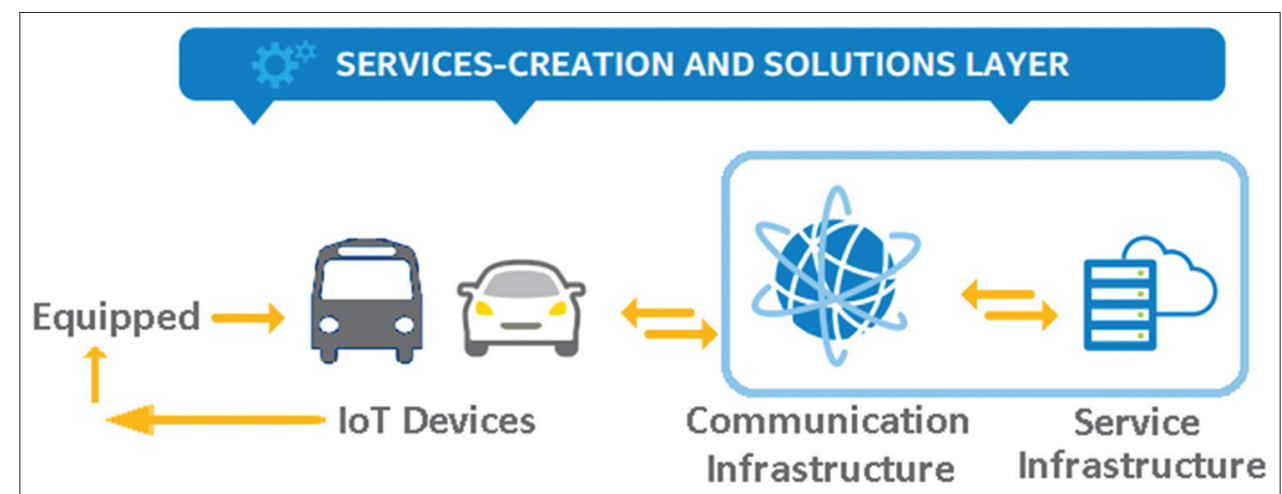

Fig. 1: Overview of proposed internet of things solution for intelligent transport system

number of devices be $v_{\mathrm{e}}$. Similarly, the average packet arrival density per device $S$ is divided into two classes: Initial $i_{s}$ and operational denoted as $u_{s}$. By considering the criss-cross interaction availability of devices and packet arrival density, the equations that describe the spread of the signals can be written as:

$$
\begin{aligned}
& \frac{d i_{e}}{d t}=\mu_{e}+A-k_{+1} i_{e}-c(S) i_{e} u_{s}+\delta v_{e} \\
& \frac{d u_{e}}{d t}=c(S) i_{e} u_{s}-\gamma u_{e}-k_{+1} u_{e} \\
& \frac{d v_{e}}{d t}=k_{-1}\left(u_{e}\right)-k_{+1} v_{e}-\delta v_{e} \\
& \frac{d e}{d t}=\mu_{e}+A-k_{+1} e \\
& \frac{d i_{s}}{d t}=\mu_{s}-k_{-1} i_{s}-\beta_{2} i_{s} u_{e}-\beta_{3} i_{s} v_{e} \\
& \frac{d u_{s}}{d t}=-k_{-1} u_{s}+\beta_{2} i_{s} u_{e}+\beta_{3} i_{s} v_{e} \\
& \frac{d S}{d t}=\mu_{s}-k_{-1} e
\end{aligned}
$$

Where, $e=i_{e}+u_{e}$ and $S=i_{s}+u_{s}$

In the system (1.1), $\mu_{\mathrm{e}}$ is priority index, $\mathrm{A}$ is the maximum delay threshold and $\mathrm{k}_{+1}$ is forward reaction rate constant. $\mathrm{c}$ is the total concentration of the enzyme-substrate complex. $\gamma$ is the recovery rate and $\delta$ is the parameter denotes the flow rate such that the $v_{e}$ will join the $\mathrm{u}_{\mathrm{e}}$ class. $\mu_{\mathrm{s}}$ is probability that the preceding delay threshold is violated and $\mathrm{k}_{-1}$ is its reverse flow rate of signals. $\beta_{2}$ and $\beta_{3}$ are the interaction rates of operational number of devices with the initial and recovered classes of the M2M devices, respectively $\left(\beta_{2}>\beta_{3}\right)$.

The model gives following two cases to be analyzed:

a. The waiting time for a queued packet c of the operating M2M devices with the infective M2M devices is a constant [19], and

b. It depends on the initial values of operational M2M units [20]. For positive constants $\mathrm{a}_{0}$ and $\mathrm{a}_{1}$, thus $\mathrm{c}$ takes the form

$$
c=a_{0}+a_{1} S \text {. }
$$

Case b is impractical at high numerical values such as ours. Therefore, we shall exempt rest of the calculation for this case.

Case A: When $\mathrm{c}=\mathrm{c}_{0} ; \mathrm{c}_{0}$ is a constant.

Since $\mathrm{i}_{\mathrm{e}}+\mathrm{u}_{\mathrm{e}}+\mathrm{v}_{\mathrm{e}}=\mathrm{e}$ and $\mathrm{i}_{\mathrm{s}}+\mathrm{u}_{\mathrm{s}}=\mathrm{S}$, the system (1) can be reduced to the form:

$$
\begin{aligned}
& \frac{d u_{e}}{d t}=c_{0}\left(e-u_{e}-v_{e}\right) u_{s}-\left(\gamma+k_{+1}\right) u_{e} \\
& \frac{d v_{e}}{d t}=\gamma\left(u_{e}\right)-\left(k_{+1}+\delta\right) v_{e} \\
& \frac{d e}{d t}=\mu_{e}+A-k_{+1} e \\
& \frac{d u_{s}}{d t}=-k_{-1} u_{s}+\beta_{2}\left(S-u_{S}\right) u_{e}+\beta_{3}\left(S-u_{s}\right) v_{e} \\
& \frac{d S}{d t}=\mu_{s}-k_{-1} e
\end{aligned}
$$

The region of attraction of the above system is

$$
\mathrm{T}_{1}=\left\{\left(\mathrm{u}_{\mathrm{e}}, \mathrm{v}_{\mathrm{e}}, \mathrm{e}, \mathrm{u}_{\mathrm{s}}, \mathrm{S}\right): 0 \leq \mathrm{u}_{\mathrm{e}}+\mathrm{v}_{\mathrm{e}} \leq \mathrm{N}_{1} \leq \overline{\mathrm{e}}, 0 \leq \mathrm{u}_{\mathrm{s}} \leq \mathrm{S} \leq \overline{\mathrm{S}}\right\}
$$

Where, $\overline{\mathrm{e}}=\lim _{\mathrm{t} \rightarrow \infty} \operatorname{supe}=\frac{\mu_{\mathrm{e}}+\mathrm{A}}{\mathrm{k}_{+1}}$ and $\overline{\mathrm{S}}=\lim _{\mathrm{t} \rightarrow \infty} \operatorname{supS}=\frac{\mu_{\mathrm{S}}}{\mathrm{k}_{-1}}$.

There exist the following three equilibra corresponding to the system (2), namely:

$$
\begin{aligned}
& \mathrm{E}_{0}\left(0,0, \frac{\mu_{\mathrm{e}}+\mathrm{A}}{\mathrm{k}_{+1}}, 0,0\right) \\
& \mathrm{E}_{1}\left(0,0, \frac{\mu_{\mathrm{e}}+\mathrm{A}}{\mathrm{k}_{+1}}, 0, \frac{\mu_{\mathrm{s}}}{\mathrm{k}_{-1}}\right) \text { and } \\
& \mathrm{E}_{2}\left(\overline{\mathrm{u}_{\mathrm{e}}}, \overline{\mathrm{v}_{\mathrm{e}}}, \overline{\mathrm{e}}, \overline{\mathrm{u}_{\mathrm{s}}}, \overline{\mathrm{S}}\right) .
\end{aligned}
$$$$
\text { Where, } \left.\begin{array}{rl}
\overline{u_{e}} & =\frac{c_{0} \overline{\mathrm{e}}\left(\beta_{2}+\frac{\beta_{3} \gamma}{\mathrm{k}_{+1}+\delta}\right)-\mathrm{k}_{-1}\left(\gamma+\mathrm{k}_{+1}\right)}{\left(\beta_{2}+\frac{\beta_{3} \gamma}{\mathrm{k}_{+1}+\delta}\right)\left\{\mathrm{c}_{0}\left(1+\frac{\gamma}{\mathrm{k}_{+1}+\delta}\right) \overline{\mathrm{S}}+\left(\mathrm{k}_{+1}+\delta\right)\right\}} \\
\overline{\mathrm{u}_{\mathrm{s}}} & =\frac{\left(\beta_{2}+\frac{\beta_{3} \gamma}{\mathrm{k}_{+1}+\delta}\right) \overline{\mathrm{S}}-\overline{\mathrm{e}}}{\left(\beta_{2}+\frac{\beta_{3} \gamma}{\mathrm{k}_{+1}+\delta}\right) \overline{\mathrm{Y}}_{1}+\mathrm{k}_{-1}}
\end{array}\right\}
$$

$$
\overline{\mathrm{v}_{\mathrm{e}}}=\frac{\gamma \overline{\mathrm{u}_{\mathrm{e}}}}{\gamma+\mathrm{k}_{+1}}, \quad \overline{\mathrm{N}}_{1}=\frac{\mu_{\mathrm{e}}+\mathrm{A}}{\mathrm{k}_{+1}}, \overline{\mathrm{N}}_{2}=\frac{\mu_{\mathrm{s}}}{\mathrm{k}_{-1}},
$$


The equilibrium $\mathrm{E}_{2}$ exists if

$$
\mathrm{R}_{0}=\frac{\mathrm{c}_{0} \overline{\mathrm{e}} \overline{\mathrm{S}}\left(\beta_{2}+\frac{\beta_{3} \gamma}{\mathrm{k}_{+1}+\delta}\right)}{\mathrm{k}_{-1}\left(\gamma+\mathrm{k}_{+1}\right)}>1
$$

We state the local stability of the three equilibria $E_{0}, E_{1}, E_{2}$ in the following theorem.

The equilibrium $E_{0}$ is stable. The equilibrium $E_{1}$ is stable if $R_{0}<1$, otherwise if $R_{0}>1$, it is unstable and the equilibrium $E_{2}$ exists and is stable if $\mathrm{q}_{1} \mathrm{q}_{2}-\mathrm{q}_{3}>0$.

The general variational matrix M corresponding to the system (2) is

$$
\mathrm{M}=\left(\begin{array}{ccccc}
-\left(\mathrm{c}_{0} \mathrm{u}_{\mathrm{S}}+\gamma+\mathrm{k}_{+1}\right) & -\mathrm{c}_{0} \mathrm{u}_{\mathrm{S}} & \mathrm{c}_{0} \mathrm{u}_{\mathrm{S}} & -\mathrm{c}_{0}\left(\overline{\mathrm{e}}-\mathrm{u}_{\mathrm{e}}-\mathrm{v}_{\mathrm{e}}\right) & 0 \\
\gamma & -\left(\mathrm{k}_{+1}+\delta\right) & 0 & 0 & 0 \\
0 & 0 & -\mathrm{k}_{+1} & 0 & 0 \\
\beta_{2}\left(\overline{\mathrm{S}}_{-} \overline{\mathrm{u}}_{\mathrm{S}}\right) & \beta_{3}\left(\overline{\mathrm{s}}-\overline{\mathrm{u}}_{\mathrm{S}}\right) & 0 & -\left(\beta_{2} \mathrm{u}_{\mathrm{e}}+\beta_{3} \mathrm{v}_{\mathrm{e}}+\mathrm{k}_{-1}\right) & \left(\beta_{2} \mathrm{u}_{\mathrm{e}}+\beta_{3} \mathrm{v}_{\mathrm{e}}\right) \\
0 & 0 & 0 & 0 & -\mathrm{k}_{-1}
\end{array}\right)
$$

At the equilibrium point $\mathrm{E}_{0}\left(0,0, \frac{\mu_{\mathrm{e}}+\mathrm{A}}{\mathrm{k}_{+1}}, 0,0\right)$, the variational matrix $\mathrm{M}_{0}$

$$
\mathrm{M}_{0}=\left(\begin{array}{ccccc}
-\left(\gamma+\mathrm{k}_{+1}\right) & 0 & 0 & \mathrm{c}_{0}\left(\frac{\mu_{\mathrm{e}}+\mathrm{A}}{\mathrm{k}_{+1}}\right) & 0 \\
\gamma & -\left(\mathrm{k}_{+1}+\delta\right) & 0 & 0 & 0 \\
0 & 0 & -\mathrm{k}_{+1} & 0 & 0 \\
0 & 0 & 0 & -\mathrm{k}_{-1} & 0 \\
0 & 0 & 0 & 0 & -\mathrm{k}_{-1}
\end{array}\right)
$$

The characteristic polynomial corresponding to the above matrix is

$\left(\mathrm{k}_{+1}+\lambda\right)\left(\mathrm{k}_{-1}+\lambda\right)^{2}\left(\mathrm{k}_{+1}+\delta+\lambda\right)\left(\mathrm{k}_{+1}+\gamma+\lambda\right)=0$

Which gives all the negative roots of $\lambda$.

Thus, the equilibrium $\mathrm{E}_{0}$ is stable. At the equilibrium point $\mathrm{E}_{1}\left(0,0, \frac{\mu_{\mathrm{e}}+\mathrm{A}}{\mathrm{k}_{+1}}, 0, \frac{\mu_{\mathrm{s}}}{\mathrm{k}_{-1}}\right)$, the variational matrix
is given by

$$
\mathrm{M}_{1}=\left(\begin{array}{ccccc}
-\left(\gamma+\mathrm{k}_{+1}\right) & 0 & 0 & \mathrm{c}_{0}\left(\frac{\mu_{\mathrm{e}}+\mathrm{A}}{\mathrm{k}_{+1}}\right) & 0 \\
\gamma & -\left(\mathrm{k}_{+1}+\delta\right) & 0 & 0 & 0 \\
0 & 0 & -\mathrm{k}_{+1} & 0 & 0 \\
\frac{\beta_{2} \mu_{\mathrm{s}}}{\mathrm{k}_{-1}} & \frac{\beta_{2} \mu_{\mathrm{s}}}{\mathrm{k}_{-1}} & 0 & -\mathrm{k}_{-1} & 0 \\
0 & 0 & 0 & 0 & -\mathrm{k}_{-1}
\end{array}\right)
$$

The characteristic polynomial corresponding to the above matrix is given by

$\left(\mathrm{k}_{+1}+\lambda\right)\left(\mathrm{k}_{-1}+\lambda\right)\left(\lambda^{3}+\mathrm{p}_{1} \lambda^{2}+\mathrm{p}_{2} \lambda+\mathrm{p}_{3}\right)=0$

Where,

$\mathrm{p}_{1}=2 \mathrm{k}_{+1}+\mathrm{k}_{-1}+\delta+\lambda$

$$
\mathrm{p}_{2}=-\mathrm{c}_{0} \beta_{2} \overline{\mathrm{e}} \overline{\mathrm{S}} \gamma-\left(\delta+\mathrm{k}_{+1}\right)\left(\mathrm{k}_{+1}+\gamma\right)+\mathrm{k}_{-1}\left(2 \mathrm{k}_{+1}+\delta+\gamma\right)
$$

$$
\mathrm{p}_{3}=-\mathrm{c}_{0} \beta_{3} \overline{\mathrm{e}} \overline{\mathrm{S}} \gamma-\mathrm{c}_{0} \beta_{2} \overline{\mathrm{e}} \overline{\mathrm{S}}\left(\mathrm{k}_{+1}+\delta\right)+\mathrm{k}_{-1}\left(\gamma+\mathrm{k}_{+1}\right)\left(\delta+\mathrm{k}_{+1}\right)
$$

We find that the Eigenvalues of (1.5) are $-\mathrm{k}_{+1},-\mathrm{k}_{-1}$ ) and the roots of the polynomial $\lambda^{3}+p_{1} \lambda^{2}+p_{2} \lambda+p_{3}$.

The above polynomial has roots with negative real part if $\mathrm{p}_{1} \mathrm{p}_{2}-\mathrm{p}_{3}>0$. Hence,

$$
\begin{aligned}
& \mathrm{p}_{1} \mathrm{p}_{2}-\mathrm{p}_{3}=\left(\gamma+\mathrm{k}_{+1}\right)^{2}\left(\mathrm{k}_{+1}+\delta\right)+\mathrm{k}_{-1}\left(2 \mathrm{k}_{+1}+\delta+\gamma\right)\left(\mathrm{k}_{+1}+\gamma+\mathrm{k}_{-1}\right) \\
& +\mathrm{c}_{0} \beta_{3} \frac{\mu_{\mathrm{s}}}{\mathrm{k}_{-1}} \gamma\left(\frac{\mu_{\mathrm{e}}+\mathrm{A}}{\mathrm{k}_{+1}}\right)
\end{aligned}
$$

Which is positive. Therefore, the stability of $E_{1}$ is given by the sign of $p_{3}$, which is positive if and only if $\mathrm{R}_{0}<1$. For $\mathrm{R}_{0}>1 \mathrm{E}_{1}$, is unstable and $\mathrm{E}_{2}$ exists.

At the equilibrium point $\mathrm{E}_{2}\left(\overline{\mathrm{u}_{\mathrm{e}}}, \overline{\mathrm{v}_{\mathrm{e}}}, \overline{\mathrm{e}}, \overline{\mathrm{u}_{\mathrm{s}}}, \overline{\mathrm{S}}\right)$, the variational matrix $\mathrm{M}_{2}$ is given by

$\mathrm{M}_{2}=\left(\begin{array}{ccccc}-\left(c_{0} \overline{\mu_{\mathrm{S}}}+\gamma+\mathrm{k}_{+1}\right) & -\mathrm{c}_{0} \overline{\mathrm{u}_{\mathrm{S}}} & \mathrm{c}_{0} \overline{\mathrm{u}_{\mathrm{S}}} & -\mathrm{c}_{0}\left(\overline{\mathrm{e}}-\overline{\mathrm{u}_{\mathrm{e}}}-\overline{\mathrm{v}_{\mathrm{e}}}\right) & 0 \\ \gamma & -\left(\mathrm{k}_{+}+\delta\right) & 0 & 0 & 0 \\ 0 & 0 & -\mathrm{k}_{+1} & 0 & 0 \\ \beta_{2}\left(\overline{\mathrm{s}}-\overline{\mathrm{u}_{\mathrm{S}}}\right) & \beta_{3}\left(\overline{\mathrm{s}}-\overline{\mathrm{u}_{\mathrm{S}}}\right) & 0 & -\left(\beta_{2} \overline{\mathrm{u}_{\mathrm{e}}}+\beta_{3} \overline{\mathrm{v}_{\mathrm{e}}}+\mathrm{k}_{-1}\right) & \left(\beta_{2} \overline{\mathrm{u}_{\mathrm{e}}}+\beta_{3} \overline{\mathrm{v}_{\mathrm{e}}}\right) \\ 0 & 0 & 0 & 0 & -\mathrm{k}_{-1}\end{array}\right)$

To give proper versatility at the most minimal expenses, the stage has been architected to keep running in an open/private cloud environment or server farms of M2M environment (Table 1). The framework tends to offer undertaking administrations crosswise over open, private and in addition crossover cloud situations. This shall helps meet necessities of information security, administrative prerequisites with reference to information stockpiling, offering undertakings control over their stockpiling and additionally network through secure passages or confined IP ranges. The administrations are provisioned and oversaw utilizing cloud APIs and are format driven, permitting administrations to be taken off rapidly and effectively. This model offers a genuinely shared methodology, and it permits our customers a "pay-as-youdevelop" business model. It permits answers for be made from pilot to industrialized worldwide take off on an anticipated and controllable expense model, utilizing a typical cloud-based environment. In particular, the stage offers uniform base that is accessible all around, along these lines empowering device free access to the cloud.

\section{Communication layer}

The uses of IoT structures a broad configuration space with numerous measurements that incorporate a few issues and parameters some of which are said beneath are as per the following:

A. Incremental and random deployment

B. Mobility infrequent or constant performed by either chose or all things in the select environment

C. Cost, size, assets, and vitality all that much asset compelled or boundless assets

D. Heterogeneity a solitary kind of thing or various arrangements of various properties and pecking orders

E. Communication methodology mainly multi-hop communication

F. Infrastructure unique applications bar, permit or require the utilization of altered base

G. Dynamic network topology: Single jump, star, multi-bounce, network or multi-level

H. Coverage-meager, thick or repetitive

I. Connectivity constant, infrequent or sporadic

J. Network size running from many hubs to thousands

K. Lifetime couple of hours, a while to numerous years

L. QoS necessities - ongoing imperatives, alter resistance, subtlety, and so on. 
Table 1: Ted bed parameters

\begin{tabular}{ll}
\hline Parameter & Value \\
\hline Overall LTE+M2M bandwidth & $22 \mathrm{MHz}$ \\
M2M bandwidth & $3 \mathrm{MHz}$ \\
LTE frame duration & $1.3 \mathrm{~m}$ \\
Number of M2M devices & $100,500,900,1500$ \\
Average packet arrival rate & $0.02 / 0.04$ packets/TTI \\
Scheduling period & $27-43 / 12-24$ TTIs \\
Network realizations & 100 \\
Realization length & $1000 \mathrm{~s}$ \\
Number of M2M classes & $6(\mathrm{HP} / \mathrm{LP})$ \\
Average HP-class packet arrival rate & $0.04 / 0.01$ packets/TTI \\
HP-class scheduling period & $35 / 55 \mathrm{TTIs}$ \\
Average LP-class packet arrival rate & $0.06-0.075 / 0.026-0.037$ \\
LP-class scheduling period & $17 / 25 \mathrm{TTIs}$ \\
Network realizations & 15 \\
Realization length & $500 \mathrm{~s}$ \\
\hline
\end{tabular}

HP: High priority, LP: Low priority, LTE: Long-term evolution, M2M: Machine to machine, TTI: Transmission time interval

Such a broad configuration space clearly makes IoT application advancement an entangled procedure. One methodology might be is to make the configuration for the most prohibitive point in the outline space, e.g. least thing capabilities, high mobility and so on. Be that as it may, regularly there it might be attractive to misuse the attributes of the different focuses in the configuration space. This infers that no single equipment and programming stage will be adequate to bolster the entire outlined configuration. Unpredictable and heterogeneous systems will be a characteristic prerequisite. Thus, ZigBee-based wireless networks are the best choice for modeling a communication layer.

Here, each ZigBee devices sends the sequence of streaming information in the form of two local posteriors which is given by: $P_{1}=\left(X^{t} \mid Z_{1}^{1: t}\right)$ and $\mathrm{P}_{2}=\left(\mathrm{X}^{\mathrm{t}} \mid \mathrm{Z}_{2}^{1: \mathrm{t}}\right)$ which are represented in the form of random finite sets with multi object densities of $\mathrm{Z}_{\mathrm{i}}^{(1: \mathrm{t})}$ observed sites. For illustration, here ZigBee devices 1 transmits its posterior to consecutive nodes where its posteriors are fused with local posterior of form a joint sequence network for sensor fusion. Here, the synchronization between such posterior is maintained as:

$$
\mathrm{P} \alpha\left(\mathrm{X}^{\mathrm{t}} \mid \mathrm{Z}_{1}^{1: \mathrm{t}}, \mathrm{Z}_{2}^{1: \mathrm{t}}\right)=\mathrm{P} \alpha\left(\mathrm{X}^{\mathrm{t}} \mid \mathrm{Z}_{1}^{1: \mathrm{t}} \cup \mathrm{Z}_{2}^{1: \mathrm{t}}\right)
$$

Now, to overcome the problem of unknown correlation between no two distributions of independent variables the solution to the fusion problem is:

$$
P_{\alpha}\left(X^{t} \mid Z_{1}^{1: t}, Z_{2}^{1: t}\right) \mu \frac{P_{\alpha}\left(X^{t} \mid Z_{1}^{1: t}\right) P_{\alpha}\left(X^{t} \mid Z_{2}^{1: t}\right)}{P_{\alpha}\left(X^{t} \mid Z_{1}^{1: t} \bigcup Z_{2}^{1: t}\right)}
$$

Hence, the generalized posterior for the scalable drone service can be represented in the form of geometric mean:

$$
P_{\alpha}\left(X^{t} \mid Z_{1}^{1: t}, Z_{2}^{1: t}\right)=\frac{P_{\alpha}\left(X^{t} \mid Z_{1}^{1: t}\right)^{\alpha 1} P_{\alpha}\left(X^{t} \mid Z_{2}^{1: t}\right)^{\alpha 2}}{\int P_{\alpha}\left(X^{t} \mid Z_{1}^{1: t}\right)^{\alpha 1} P_{\alpha}\left(X^{t} \mid Z_{2}^{1: t}\right)^{\alpha 2} \delta X}
$$

Where, $\alpha 1, \alpha 2(\alpha 1+\alpha 2=1)$ the parameters determining the relative fusion weight of each nodes.

\section{Cloud-based service layer for cloud two cloud interaction}

The composition and deployment of these new services will be possible through the use of cloud to cloud technologies. The cloud approach will ease the reuse of data provided by different devices. A simple view of the infrastructure is given to existing but also new service provider.
One of the difficulties in building IoT applications in the given context is the way to plan a common underlying software fabric for various situations and how to assemble a cognizant application out of a huge gathering of assorted software modules. A significant measure of innovative work effort is presently centered around service-oriented processing for creating disseminated and combined applications to support interoperable streaming data from cloud-to-cloud, machine-tomachine, and thing-to-thing interaction over a network. This is based on the internet protocols, and on top of that, one requires to characterize new protocols to portray and address the service examples. Service oriented processing freely organizes the web and cloud to cloud services and makes it a virtual network. This can be modeled as flows:

Let $\mathrm{p}$ be the set of points for $\left\{\mathrm{p}_{1}, \mathrm{p}_{2}, \ldots, \mathrm{p}_{\mathrm{n}}\right\}$ where the contextual streaming data are embedded based on its geographical locality where a function $\overline{\mathrm{F}}$ is defined to gauge the closing distance between:

$$
S=\left\{p_{1}(u, v, z) p_{2}(u, v, z), p_{2}(u, v, z) p_{3}(u, v, z), \ldots, p_{i}(u, v, z) p_{j}(u, v, z)\right\}
$$

And a set of other points in $(\mathrm{u}, \mathrm{v}, \mathrm{z})$ coordinate system. Thus, the energy function or global distance of a surface is a weighted area where each element of this surfaces is weighted in correspondence with its distance to its closest point in the data set $\Sigma$.

$$
\overline{\mathrm{F}}(\mathrm{S})=\left(\int_{\mathrm{x} \in \mathrm{S}} \mathrm{d}^{\mathrm{p}}(\mathrm{x}) \mathrm{ds}\right)^{1 / \mathrm{p}}, 1 \leq \mathrm{p} \leq 4
$$

Where $d(x)$ is the distance from $x \in I^{3}$ to its closest point in $S$.

We can utilize this function for detailing the development of a variational formulation of an evolution equation to construct this minimal cloud to cloud routing in multiple streams to withstand the delay in data dissemination and processing for real-time applications such as traffic behavior modeling and traffic delay calculation. Therefore, at every iteration the evolution equation runs a gradient descent of the energy function to get it minimized. At each step, every point $\mathrm{x}$ of the stream $\mathrm{S}(\mathrm{t})$ at time $t$ multicast toward the other local clouds along the normal stream direction to $\mathrm{S}(\mathrm{t})$ at point $\mathrm{x}$, with a displacement speed that is relative to:

$$
\frac{d(x) K}{T}-\nabla d(x) \cdot \vec{n}
$$

Where, $\vec{n}$ is the bid profile vector between local clouds to gain the streaming data at $\mathrm{x}$ coordinate position and $\mathrm{K}$ is a notation denoting the mean payoff at $\mathrm{x}$. The aggregation of the bid profile is represented byte first term $\frac{d(x) K}{T}$ which is non-linear, such that the evolution process requires a certain number of steps before reaching its equilibrium.

Therefore, taking in account of the effects of both bid profile and the concession for cloud negotiation through cloud agent can be put forth in the form of graph topology represented as a graph $G=(V, E)$, with vertices $\mathrm{V}$ and edges $\mathrm{E}$ are the aggregate conflict probability and counter bid proposal. Thus, the probability of cloud agent to reach out with counter proposal to gain streaming data can be globally represented as

$\operatorname{TD}(\mathrm{x})=\sum_{\mathrm{i}=1}^{\mathrm{n}} \varphi_{\mathrm{i}}(\mathrm{x}) \mathrm{v}_{\mathrm{i}}$

Where TD is the complete topology, $\varphi_{i}$ is the continuous piecewise basis function of the vertices ( 1 or 0 if $\mathrm{i}=\mathrm{j}$ or otherwise) for the $\mathrm{i}^{\text {th }}$ vertex in which $x \in \mathrm{R}^{3}$. Given that we have external cloud negotiation vector $\mathrm{F}_{\mathrm{V}}^{\mathrm{ext}}=\left[\mathrm{f}_{1}^{\mathrm{ext}}, \mathrm{f}_{2}^{\mathrm{ext}}, . ., \mathrm{f}_{\mathrm{n}}^{\mathrm{ext}}\right]^{\mathrm{T}}$, which tends to minimize the energy function for both external and internal cloud negotiation between cloud agents is given by.

$$
\mathrm{S}_{\mathrm{t}} \mathrm{V}=\mathrm{F}_{\mathrm{V}}^{\mathrm{ext}}
$$




$$
\mathrm{S}_{\mathrm{t}} \mathrm{f}_{\mathrm{i}}^{\mathrm{int}}=\sum_{(\mathrm{i}, \mathrm{j}) \in \mathrm{E}} \mathrm{a}_{\mathrm{ij}}\left(\mathrm{v}_{\mathrm{i}}-\mathrm{v}_{\mathrm{j}}\right)
$$

Where the conflict matrix is represented by $S_{t}$, whose size is $n \times n$. is the vector of control vertices of the streaming data and its division point. It the control vertices can be precisely illustrated for the $i^{\text {th }}$ row and $j^{\text {th }}$ column streaming element of $\mathrm{S}_{\mathrm{t}^{\prime}} \mathrm{a}_{\mathrm{ij}}$ as:

$$
A_{i j}=\left\{\begin{array}{c}
\int_{T D}\left(\nabla \varphi_{i} \cdot \nabla \varphi_{j}\right) d T D, i=j o r ~(i, j) \in E \\
0, \text { otherwise }
\end{array}\right.
$$

Using finite differences in time, the multicast distribution of streaming data of the model can be iteratively represented as:

$$
\frac{\mathrm{V}^{(\mathrm{t})}-\mathrm{V}^{(\mathrm{t}-1)}}{\theta}+A V^{(\mathrm{t})}=\mathrm{F}_{\mathrm{V}^{\mathrm{t}-1)}}^{\mathrm{ext}}
$$

Where $\mathrm{V}^{(\mathrm{t})}$ is the vector of the model's vertices at the $\mathrm{t}^{\text {th }}$ position, and $\theta$ is the time step size. Upon combining the effects of both external and internal cloud negotiation bid profiles, we get the final combined effects of conflict probability of cloud-to-cloud system:

$$
\mathrm{V}^{(\mathrm{t})}=\left(\mathrm{F}_{\mathrm{V}^{(\mathrm{t}-1)}}^{\mathrm{ext}}+\mathrm{f}_{\mathrm{V}^{(\mathrm{t}-1)}}^{\mathrm{int}}\right) \theta+\mathrm{V}^{(\mathrm{t}-1)}
$$

The above model avails to supportan extensive variety of uses and address common necessities from an extensive variety of industry sectors and in addition the requirements of nature, society, and individual natives. Through accord forms including different partners, it will be conceivable to create standardized semantic information models and ontologies, common interfaces and protocols, at first characterized at a dynamic level, then with case bindings to particular cross-platform, cross-language technologies, for example, XML, ASN.1, web services and so forth. Instead of utilization of semantic ontologies, we used mathematically modeled machine-coherent codification which ought to overcome ambiguities because of human error or contrasts and confusion because of various programming languages and in addition assisting with cross-referencing to extra information accessible through different systems. Standards are required for bidirectional communication and information trade among things, their surroundings, their advanced partners in the cloud-tocloud communication, stream distribution and substances that have an enthusiasm for monitoring, controlling or assisting the IoT.

\section{RESULTS AND DISCUSSION}

Platform interoperability is currently based on non-standardized solutions which make it difficult to propose new services involving different business domains. To overcome this issue, we formulated the model for M2M and cloud to cloud communication which is defined on horizontal end-to-end M2M services platform. This platform is based on existing and well-established communication standards and norms. It has been designed to support multiple services independently from the underlying networks or the considered business domain. This M2M high-level system architecture embraces the principle of services exposed to applications. These services can be located in a network, a device, or a gateway. A notable aspect of this view is the provision of an end-to-end representation of the M2M + cloud-to-cloud system, where other elements of this architecture such as the distributed management of the streaming data and are integrated under the same study.

The proposed work enabled ITS. This architecture defines mandatory and optional elements and interfaces of an ITSC. In this architecture, a clear distinction is made between the ITS domain and the generic domain. The basic unit of an ITSC is the station and 4 functional subsystems. Each of these ITS subsystems contain an ITS station. The functionality of an ITS station may be implemented in a single physical unit or several units. As in the M2M architecture, the standard ITS architecture defines the following functional components as part of an ITS station. Both M2M and ITS architectures may lead to understanding that each architecture is dedicated to specific scenarios. However, for the delivery of new and rich applications, interoperability between different platforms is needed. Such interoperability presented in this work will pave the way to a whole new business model with new actors' roles such as communications provider, sensors provider, and data mules providers but also application providers. The innovation of this project consists on augmenting ETSI standardization works in the fields of M2M and ITS and proposing new functionalities.

\section{CONCLUSION}

The significance of conjoining M2M and intercloud communication is twofold. First, it enables intelligent interactions between cloud-to consumer for several IoT applications such as intelligent transportation system and the other is to model the economics of cloud services. Being this work first to model the coalition between multiple devices and multiple cloud based on data stream distribution with approximation to achieve perfect equilibrium has high payoff. This game-theoretic approach for modeling such a vast system will lay the foundation of IoT economics.

\section{REFERENCES}

1. Zanella A, Bui N, Castellani A, Vangelista L, Zorzi M. Internet of things for smart cities. IEEE Internet Things J 2014;1(1):22-32.

2. Salim KA, Idrees IM. Design and implementation of web-based GPSGPRS vehicle tracking system. IJCSET 2013;3(12):443-8.

3. Yongjun Z, Xueli Z, Shuxian Z, Shenghui G. Intelligent Transportation System Based on Internet of Things. World Automation Congress; 2012.

4. Atzori L, Iera A, Morabito G. The internet of things: A survey. Comput Netw 2010;54(15):2787-805

5. Al-Sakran HO. Intelligent traffic information system based on integration of internet of things and agent technology. Int J Adv Comput Sci Appl 2015;6(2):37-43

6. Xiao L. Internet of things: A new application for intelligent traffic monitoring system. J Netw 2011;6(6):887-94.

7. Ashton K. That internet of things thing. RFID J 2009;22:97-114.

8. Singh D, Tripathi G, Jara AJ. A Survey of Internet of Things: Future Vision, Architecture, Challenges and Services. IEEE World of Forum on Internet of Things; 2014.

9. Chepuru A, Rao KV. A study on security of IoT in intelligent transport systems applications. Int J Adv Res Comput Sci Softw Eng 2015;5(9):693-700.

10. Yin Y, Dalin J. Research and Application on Intelligent Parking Solution Based on Internet of Things, $5^{\text {th }}$ International Conference on Intelligent Human-Machine Systems and Cybernetics (IHMSC); 2013.

11. Bandyopadhyay D, Sen J. The internet of things - Applications and challenges in technology and standardization. Springer Int J Wirel Pers Commun 2011;58(1):49-69.

12. Katiyar V, Kumar P, Chand N. An intelligent transportation system architecture using wireless sensor network. Int J Comput Appl 2011;14(2):22-6

13. Lo'pez TS, Ranasinghe DC, McFarlane D, Harrison M. Adding sense to the internet of things an architecture framework for smart object systems. Pers Ubiquitous Comput 2012;16(3):291-308.

14. Yulian C, Wenfeng L, Zhang J. Real-Time Traffic Information Collecting and, Monitoring System Based on the Internet of Things, $6^{\text {th }}$ International Conference on Pervasive Computing and Applications (ICPCA), IEEE; 2011.

15. Sehgal A, Perelman V, Kuryla S, Schonwalder J. Management of resource constrained devices in the internet of things. IEEE Commun Mag 2012;50(12):144-9.

16. Rai A. Shell implementation of neural net over the UNIX environment for file management: A step towards automated operating system. J Oper Syst Dev Trends 2014;1(2):10-4.

17. Rai A. An introduction of smart self-learning shell programming interface. J Adv Shell Program 2015;1(2):3-6.

18. Rai A, Ramanathan S, Kannan RJ. Quasi Opportunistic Supercomputing for Geospatial Socially Networked Mobile Devices. Enabling Technologies: Infrastructure for Collaborative Enterprises (WETICE), 2016 IEEE $25^{\text {th }}$ International Conference on IEEE; 2016.

19. Rai A. Air Computing: A parallel computing module for offloading computational workload on neighboring android devices. Recent Trends Parallel Comput 2015;1(3):10-3.

20. Rai A, Ramanathan S. Distributed learning in networked controlled cyber physical system. Int J Pharm Technol 2016;8(3):18537-46. 